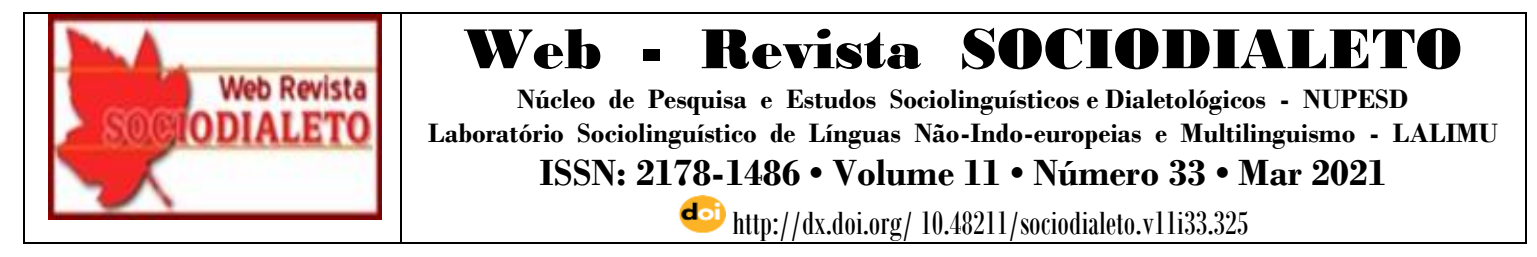

\title{
A LÍNGUA DE SINAIS NA CONSTRUÇÃO DA IDENTIDADE DOS SURDOS NO MUNICÍPIO DE JI-PARẢNÁ
}

\section{SIGN LANGUAGE IN THE CONSTRUCTION OF DEAF IDENTTY IN THE MUNICIPALITY OF JI-PARANA}

\author{
Flavia Regina Stur (Faculdade São Lucas) ${ }^{1}$ \\ sarahstur@hotmail.com \\ Rosiane Ribas de Souza Eler (UNEMAT) ${ }^{2}$ \\ rosiane.ribas@unir.br \\ Olga Maria da Mota (UNIR) ${ }^{3}$ \\ olga.maria@unir.br
}

Rosangela Santos (UNIASSELVI)

rosasantos1979@hotmail.com

\begin{abstract}
RESUMO: A presente pesquisa tem como objetivo evidenciar fatos da história que contribuíram para construção da identidade dos surdos, relatando os acontecimentos do início da instrução e aprendizado da Língua Brasileira de Sinais - LIBRAS para a maioria dos surdos e alguns ouvintes em meados de 2001 até os dias atuais e as conquistas alcançadas pela comunidade surda no município de Ji-Paraná/Rondônia. Para a produção dos dados, foram realizadas entrevistas semiestruturada a surdo, intérpretes e envolvidos neste processo, evidenciando dados interpretativos de relevância e que ainda não havia sido registrados / catalogados. A iniciativa das instituições educacionais e religiosas foram essenciais para ensino e aprendizagem da Libras e com isso, os surdos se fizeram protagonistas da sua história nesse meio social.
\end{abstract}

PALAVRAS-CHAVE: LIBRAS; Surdos; Aprendizado.

ABSTRACT: The present research aims to evidence facts from history where the beginning of instruction and learning of the Brazilian Language of Signals - LIBRAS for the majority of the deaf and some listeners in the middle of 2001 until the present day and the achievements achieved by the deaf community in the municipality of Ji-Paraná / Rondônia. For the collection of the facts, semi-structured interviews were conducted with the deaf, interpreted andinvolved in this process, showing relevant interpretative data and not yet recorded / cataloged. The initiative of educational and religious institutions was essential for

\footnotetext{
${ }^{1}$ Graduada em Pedagogia pela Universidade Luterana do Brasil - ULBRA, Graduanda em Licenciatura em Letras Libras pelo Centro Universitário Leonardo da Vinci - UNIASSELVI; e professora de Língua Brasileira de Sinais na Faculdade São Lucas.

${ }^{2}$ Doutoranda em Linguística pela Universidade Estadual do Mato Grosso - UNEMAT e professora de Língua Brasileira de Sinais do departamento de Ciências Humanas - Campus de Ji-Paraná da Universidade Federal de Rondônia - UNIR.

${ }^{3}$ Mestre em Letras pela Universidade Federal de Rondônia - UNIR e professora de Língua Brasileira de Sinais do departamento de Pedagogia - Campus de Guajará Mirim da Universidade Federal de Rondônia - UNIR.

${ }^{4}$ Graduada em Licenciatura em Matemática pela Universidade Federal de Rondônia - UNIR; professora, graduanda em Licenciatura em Letras Libras pelo Centro Universitário Leonardo da Vinci - UNIASSELVI.
} 


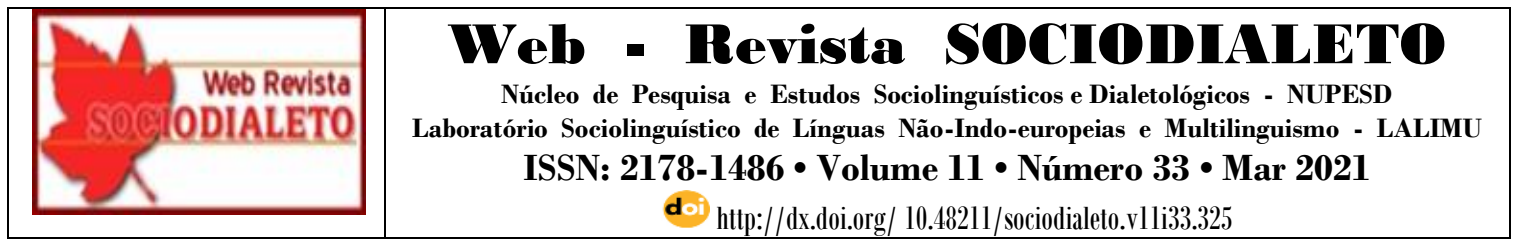

the teaching and learning of Libras and with this, the deaf became protagonists in society.

KEYWORDS: LIBRAS; deaf; learning.

\section{INTRODUÇÃ̃o}

A pesquisa científica objetiva contribuir para a evolução do conhecimento humano, explorando o meio, comprovando fatos e fornecendo conhecimentos pertinentes a análise e interação do passado e presente, onde suas causas influenciam nos acontecimentos atuais e do futuro. Havia no município surdos que não se comunicavam por meio de sua língua natural, a Língua Brasileira de Sinais - LIBRAS e, por meio desta pesquisa, os dados puderam mostrar o tempo, os personagens e as instituições que fizeram parte destes acontecimentos históricos, culturais e sociais importantíssimos na vida dos surdos. Desde o início, a trajetória do ensino e a aprendizagem da Libras e as conquistas da comunidade surda no período entre os anos de 2000 até os dias atuais, no município de Ji-Paraná (Rondônia).

A pesquisa com abordagem qualitativa, descritiva, contou como instrumento de coleta de dados entrevista semiestruturada que ocorreram entre os meses de outubro/novembro do ano de 2018, com: surdos, intérpretes e indivíduos envolvidos, sendo estes de instituição educacionais (secretarias de educação estadual e municipal) e religiosa (igreja evangélica) do município citado. Os dados coletados dão uma dimensão de todo o contexto histórico que permeia a vivência do surdo, sua cidadania e a compreensão deste indivíduo no meio social.

\section{CONTEXTO HISTÓRICO DA EDUCAÇÃO DE SURDOS NO MUNDO}

A primeira comunicação usada na pré-história era por meio das mãos e somente depois foi substituído pela comunicação oral. VYGOTSKY (1987) apud REILY (2004, p. 113) nos diz que: “[...] os homens pré-históricos trocaram a comunicação gestual pela comunicação oral, pela palavra, quando começaram a utilizar ferramentas; trabalhando com as mãos ocupadas, precisaram inventar uma alternativa para dialogar". A comunicação gestual se perdeu com o tempo e somente os surdos a utilizavam por 


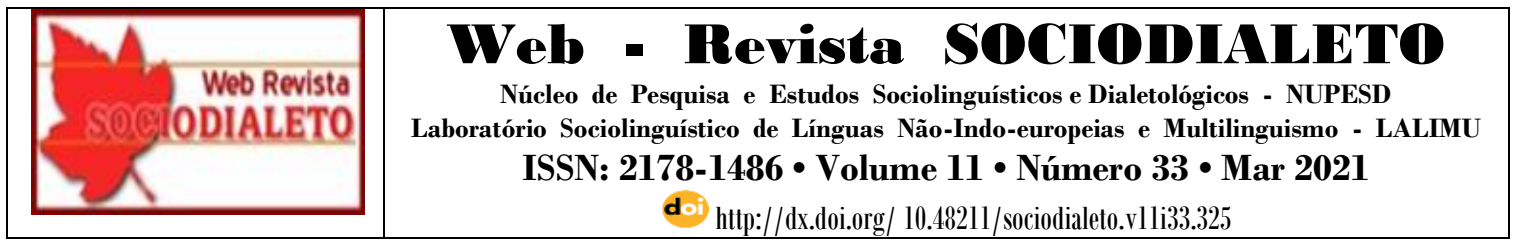

necessidade, porém, os ouvintes sendo a maioria, entenderam que esse meio de comunicação era inferior, sem sentido, uma vez que a oralidade trazia a praticidade a todos . A comunicação dos surdos, minoria (gestual/sinais), trouxe na história uma série de dificuldades sociais, os surdos eram vistos como primitivo e não educável.

$\mathrm{Na}$ antiguidade os surdos eram considerados seres incompetentes por não falar oralmente e eram abandonados pelos familiares. "O filosofo heródoto classificava os surdos como 'seres castigados pelos deuses'." (STROBEL, 2009, p. 18). Na China e na Grécia os surdos ou qualquer pessoa que tinha uma deficiência eram lançados ao mar, ou abandonados pelas famílias, algumas os escondiam, também eram usados como bobos da corte. Também não eram considerados como humanos pela igreja católica pelo fato de não poder 'confessar os pecados', não podiam herdar os bens da família e a casarse. (REILY (2004).

A partir dos séculos XV é que que temos os primeiros registros de professores que se dedicaram ao ensino dos surdos filhos de nobres treinando-os a falar, assim os surdos não perdiam suas posições e as famílias destes, continuavam a manter Santa Madre Igreja como forma de receber benefícios financeiros. Em 1500 temos Giralamo Cardano, que utilizava a escrita e a língua de sinais com os surdos, na Espanha monge chamado Pedro Ponce de León que instituiu a primeira escola para surdos (em Madri), ele se dedicava a ensinar os surdos de famílias nobres. Ele desenvolveu um alfabeto manual, para ajudar os surdos a soletrarem as palavras.

Um dos grandes precursores do reconhecimento da língua de sinais foi Charles Michel de L'Epée (1712-1789), que fez um trabalho com duas surdas, utilizava gestos, que hoje reconhecemos como sinais, e ensinou vários surdos carentes que pererambulavam por Paris nessa época (REILY, 2004). Ele fundou o Instituto para Jovens Surdos e Mudos de Paris, a primeira escola pública para surdos, que devido a esse trabalho foi reconhecido como ser humano e usuário de uma língua visual-gestual, ele treinou vários professores surdos que levaram adiante o ensino para surdos no século XVIII.

A língua de sinais iniciou-se no Brasil depois de 1857. Segundo REILY (2004, p. 


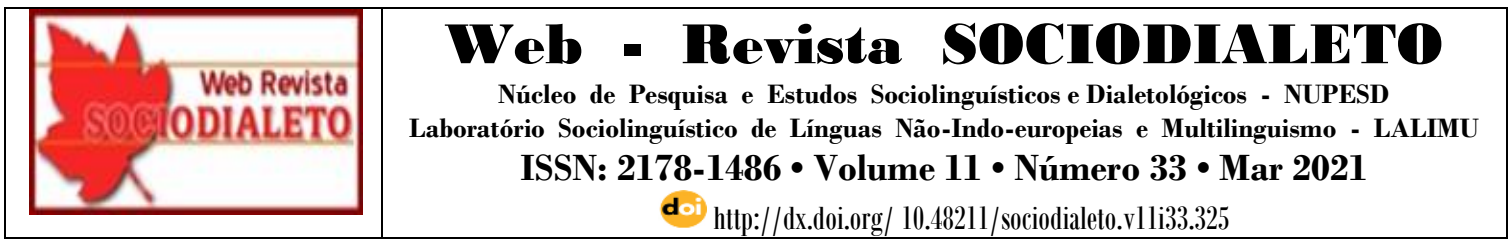

114), “A língua de sinais que conhecemos hoje no Brasil, utilizada pelos surdos, teve origem na sistematização realizada por religiosos franceses". Isso aconteceu por iniciativa de D. Pedro II ao convidar o professor francês surdo Eduard Huet para vir ao Brasil trabalhar com os alunos surdos, pois naquela época os surdos não possuíam evolução na aprendizagem por falta de apoio e incentivo do governo e das famílias.

[...] Eduard Huet, um professor que estudou no Instituto de Surdos de Paris, um dos primeiros fundados para a educação do indivíduo surdo no mundo. A fundação da primeira escola para surdos no Brasil teve apoio do Imperador D. Pedro II, essa escola atualmente chamada Instituto Nacional de Educação de Surdos (INES) é referência na área da surdez no Brasil, registrando a partir da sua criação a história da educação de surdos no Brasil. (ELER, 2020, p. 42).

Com essa iniciativa de D. Pedro II em 1857, foi criada a primeira escola para surdos no Brasil com base na Lei 939 de 26 de janeiro de 1857 chamado de Imperial Instituto dos Surdos-mudos (REILY, 2004).

Em 1880 houve um congresso em Milão na Itália que mudou a rumo da educação de surdos em todo o mundo, foi decidido por professores ouvintes que a melhor metodologia para o ensino de surdos era o oralismo. Assim ficou decretado a nível mundial o ensino por meio do oralismo (linguagem articula e leitura labial). Por mais de cem anos, essa metodologia prevaleceu e, somente após um século de privação da língua natural, iniciou- se a passos lentos e por necessidade o uso gradual da língua de sinais.

\section{A LÍNGUA DE SINAIS EM JI-PARANÁ}

A pesquisa foi realizada no município de Ji-Paraná, estado de Rondônia-Brasil, segundo o censo do IBGE de 2010, o município possui 116.610 habitantes. Esta teve como objeto de pesquisa surdos, intérpretes e envolvidos (tanto integrantes de comunidades religiosas como profissionais da área da educação). Os participantes da pesquisa serão identificados com letras e números, assegurando a privacidade dos mesmos. 


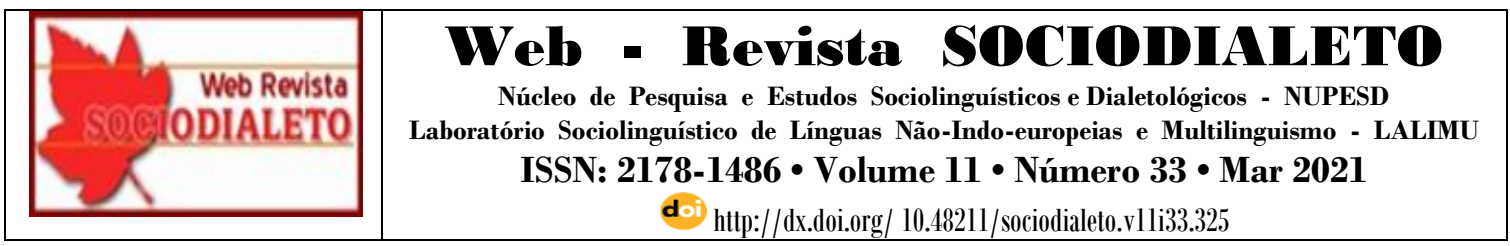

\section{QUADRO 1 - Descrição dos participantes da entrevista}

\begin{tabular}{|l|l|}
\hline Entrevistados & Identificação \\
\hline Surdos & SK \\
\hline Intérpretes & In1; In2 \\
\hline Envolvidos & E1; E2; E3; E4 (ouvintes) \\
\hline
\end{tabular}

Participaram desta pesquisa o total de 07 pessoas. Foi exposto aos participantes o objetivo e relevância da pesquisa, onde todos participaram de forma livre assinaram o termo livre e esclarecido.

\section{QUADRO 2 - Caracterização das pessoas envolvidas na entrevista}

\begin{tabular}{|c|l|}
\hline Identificação & Ano e Envolvimento \\
\hline SK & $\begin{array}{l}\text { 2004 - A sua professora de matemática instruiu a família sobre ensino da Libras } \\
\text { 2005 - Iniciou o contato com a Libras } \\
\text { 2006 - Fez curso de Libras em PVH e começou a atuar como instrutor de Libras; }\end{array}$ \\
\hline In1 & 2002 - Intérprete de comunidade religiosa; \\
\hline In2 & $\begin{array}{l}\text { 2002 - Intérprete comudidade religiosa e membro da diretoria da Associação } \\
\text { de Surdos e Familiares - ASFJIPA. }\end{array}$ \\
\hline E1 & Integrante de comunidade religiosa/prima de um surdo \\
\hline E2 & 2000 - Mãe de surdo e professora/intérprete de surdos \\
\hline E3 & $\begin{array}{l}\text { 2004 - Juntou-se com outras professoras para aprender Libras por meio de CD } \\
\text { do INES; }\end{array}$ \\
\hline E4 & $\begin{array}{l}\text { 2000 - Foi ao INES e participou de curso; criou o primeiro projeto voltado para } \\
\text { os surdos, envolvendo 43 surdos; }\end{array}$ \\
\hline
\end{tabular}

FONTE: Coleta de dados nas entrevistas

A entrevista semiestruturada realizada com surdos, intérpretes e envolvidos mostram dados que proporcionam a visualização dos fatos cronológicos da história do ensino e aprendizagem da Libras e as conquistas da comunidade surda dos anos de 2001 até os dias atuais.

Os Ji-Paranaenses ouvintes e a maioria dos surdos não se comunicavam em língua de sinais até o ano de 2000, a interação se realizava por diferentes formas de comunicação, ou seja, era a comunicação total, que é a mistura de sinais da Libras com 


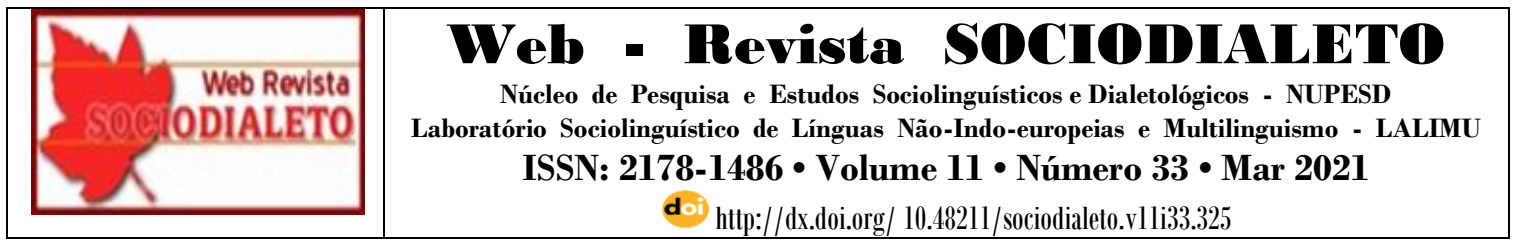

a estrutura do português e a língua falada, conforme Farias (2006) "“...] que preconizam o Português sinalizado como técnica importante para o acesso à língua-alvo para os surdos." (262). Exceto alguns surdos que viajavam pelo Brasil vendendo alfabeto manual, esses sabiam Libras que aprenderam nessas viagens.

Diante destas estratégias, muitos surdos tinham a concepção que ao balbuciar, os ouvintes conseguiam compreendê-los, outros usavam gestos caseiros, dentre outros. Todas essas tentativas também eram usadas por familiares e até profissionais da educação deste período. Até o ano de 1996, os alunos surdos participavam de aulas na Associação de Pais e Amigos dos Excepcionais - APAE, havia uma professora que trabalhava com esses alunos surdos usando uma cartilha da metodologia comunicação total, assim ensinava sinais no atendimento escolar. Conforme nos relata E2: "Essa professora que trabalhava com surdos quando eles eram crianças, quando eles ficavam na $A P A E$ ", segundo E2 esta professora ensinava português sinalizado, mas não era um ensino sistematizado e contextualizado. O contato que houve na APAE não fez com que estes alunos tivessem a língua de sinais, apenas alguns sinais aleatórios.

A partir de 1997, devido a Lei de Diretrizes e Bases - LDB 9394 de 20 de dezembro de 1996, os alunos surdos que estudavam nessa turma especial na Apae foram enviados para as escolas regulares para serem integrados.

Os surdos foram integrados nas escolas regulares, sem acesso a língua de sinais, na sala de aula observavam professores e alunos ouvintes conversando e tentavam fazer a leitura de expressões faciais e corporais para compreender o que estava acontecendo, não tendo êxito no aprendizado acadêmico.

Durante a pesquisa de onde iniciou e como iniciou o aprendizado da língua de sinais em Ji-Paraná, ficou evidente dois ambientes com objetivos distintos as instituições educacionais e religiosas, que iniciaram o acolhimento, ensino da língua e o envolvimento com os surdos entre os anos de 1999 a 2002. Na educação pública estava iniciando as discussões sobre a educação inclusiva, e os problemas com esses alunos integrados desde 1997 e que não estavam avançando em aprendizado acadêmico. 


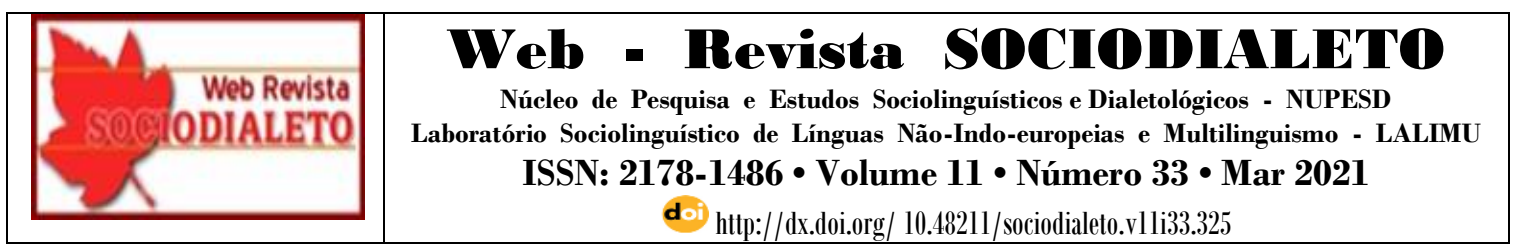

Em março de 2000, a SEDUC/REN, enviou E4 ao Instituto Nacional de Educação de Surdos - INES, localizado no Rio de Janeiro, para participar de uma capacitação que o Instituto oferecia 'Curso de Estudos Adicionais para professores na área da Deficiência Auditiva', objetivando compreender a complexidade da surdez e as necessidades específicas da comunidade surda para dar atendimento adequado a essa demanda. $\mathrm{O}$ envolvimento com os surdos do INES, fez com que despertasse em E4 o anseio de organizar um projeto voltado para os surdos do município. Como E4 trabalhava na área de informática, idealizou o projeto 'O surdo e o computador' conforme nos relata E4:

"conhecer um pouco da complexidade do dia a dia dos surdos, fez com que nossa visão de educação vislumbrasse além do nosso cotidiano, o que nos motivou em desenvolver um trabalho educacional específico para os surdos, com o uso dos recursos computacionais, culminando no Projeto "O Surdo e o Computador", o qual foi executado no NTE - REN/SEDUC/JPR/RO, a partir de 2001 a 2005. O projeto primava pelo envolvimento de outros profissionais, sendo que durante sua execução diversos adeptos como professores, estudantes, pais e alguns voluntários da sociedade de JiParaná, aderiram ao trabalho, ajudando na construção de um contexto educacional mais apropriado e adequado ao surdo Ji-Paranaense".

Na Secretaria do Estado de Educação - SEDUC, atual Coordenadoria Regional de Ensino - CRE, antiga Representação de Ensino - REN, em 2001 iniciou o projeto o 'Surdo e o Computador' e a II Igreja Batista ofertou o primeiro Curso Básico de Libras.

O aprendizado da Libras surgiu como ponto norteador na vida desses surdos a partir da interação entre seus pares e os ouvintes, promovendo nos surdos o interesse e o encantamento pela língua de sinais. Segundo E2 conta como foi esse processo de chegada dos surdos e seu aprendizado da língua:

"Um surdo, que hoje trabalha em um laticínio da cidade, chegou no escola sem saber Libras, sem comunicação com os outros surdos, com três meses de contato com seus pares linguísticos estava fluente em Libras. Tivemos exemplo de outro surdo que era do sítio, ele chegou sem Libras nenhuma, mas ele tinha uma comunicação caseira no sítio com a família, então rapidamente ele trocou aqueles sinais caseiros por sinais de Libras e começou a se comunicar normalmente junto com os surdos. Assim, os surdos que não sabia Libras com três a quatro meses de contato com o grupo de surdos fluentes na língua de sinais, passavam a se comunicar também fluentes em Libras." 


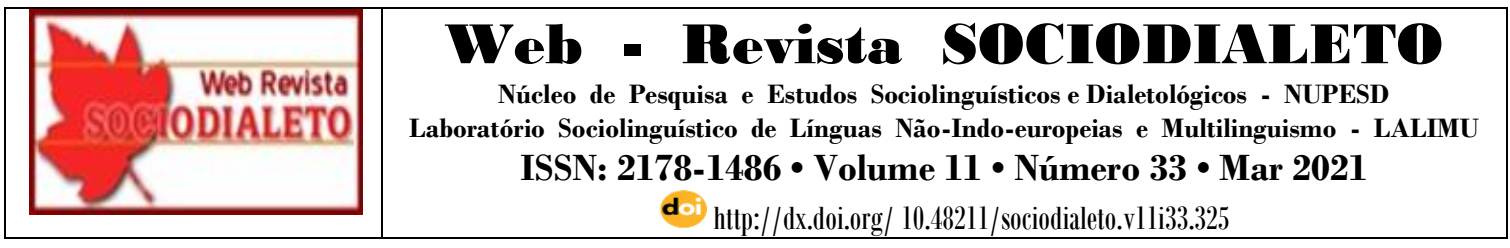

O Projeto abriu espaço para estágios, participou como estagiaria uma acadêmica do Sistema de Informação da ULBRA no Projeto, no período de fevereiro de 2002 até julho de 2003, permaneceu no Projeto, integrando o grupo de voluntários, estabelecendo uma parceria para implementar um software para auxiliar no ensino do português escrito, conhecido como Catálogo Digital.

Além do projeto no NTE/REN, houve a experiência em outra instituição, a religiosa. Uma igreja composta por pessaoas com o desejo de evangelizar junto aos familiares de surdos, vendo a situação do surdo de participar da igreja e não haver comunicação, decidiram organizar o projeto de ensino de Língua de Sinais com objetivo de trazer mais surdos para que juntos pudessem participar e ser evangelizados, formaram assim, o Ministério de Surdos da II Igreja Batista de Ji-Paraná. Segundo Silva (2013), a ação religiosa desde o século XVI, tem um papel importante na construçao da alteridade e contribuido para reflexão de como pensar o outro em povos isolados e desconhecidos. Com seu objetivo em traduzir a bíblia, faz um mergulho na cultura e no ambiente desses povos:

\begin{abstract}
A missão cristã sempre teve que se haver em um plano prático comunicativo com a sistematização/produção da cosmologia e da língua do outro. Por conta disso, as atividades missionárias cristãs, em suas experiências de longa duração, em um processo, acabaram por influenciar as ciências socias nascentes no final do século XIX que refletem sobre o outro, o que explicaria o fato de categorias como a religião e a cultura travarem relações de equivalência ou mesmo de de sinonímia. ( SILVA, 2013, p. 07).
\end{abstract}

Ao analizar a e o desenvolvimento da língua de sinais por essa comunidade, não se pode negar o papel que as atividades missionárias cristã tiveram na organização da comunidade surda de Ji-Paraná e o desenvolmento da língua de sinais, como cita Silva (2013). Segundo a pessoa entrevistada denominada como E1, prima de um surdo, nos diz que: “Nessa época não havia nenhum trabalho com surdos nas igrejas ou em outros órgãos, aqui na cidade. Pensei em fazer esse trabalho porque achei interessante inserir os surdos no contexto religioso". Esse fato nos remete ao que ROSA (2005, p. 92) nos 


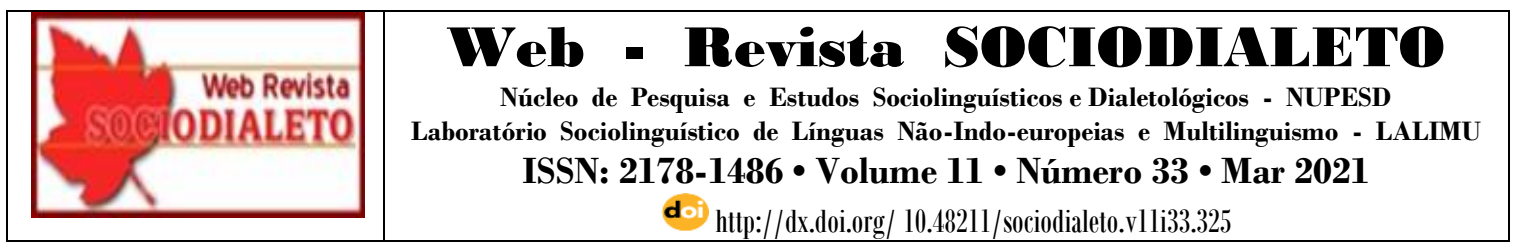

diz: "No Brasil a atividade de interpretação ocorre com maior frequência nas instituições religiosas; aliás, nesses a atuação do ILS tem sido uma prática há décadas, mais exatamente desde o início dos anos 80 (...)”. A preocupação em levar o evangelho e incluir a todos, no caso os surdos, favoreceu o aprendizado da Libras tanto aos surdos como os ouvinte de Ji-Paraná neste espaço religioso.

O trabalho das igrejas protestantes contribuiram para nova visão do surdo que tem língua, cultura e história. “[...] a produção efetiva dos sinais como língua independente do português deu-se, sobretudo em domínios protestantes(luteranos e batistas)." (SILVA, 2013, p. 14). Assim, em Ji-Paraná a II Igreja Batista organizou um curso de Libras ministrado por um surdo do município de Cacoal, de acordo com E1:

“(...) trouxemos um surdo de Cacoal, Marcio, era da $1^{a}$ Igreja Batista de Cacoal e ele veio para ministrar o curso de Libras para os surdos da igreja. Antes disso a maioria dos surdos da igreja só se comunicavam por sinais caseiros, eles não conheciam Libras como língua de sinais, a partir daí o grupo de surdo começou a disseminar a Libras e a secretaria estadual da educação também tinha um trabalho com os surdos voltado para a informática onde eles também aprendiam Libras".

O aprendizado da língua de sinais aconteceu ao mesmo tempo com surdos e envolvidos pela causa, segundo a Intérprete, identificada como In1, diz: "Me lembro como se fosse hoje, os surdos aprendendo a datilologia de seus nomes. Aprendemos juntos. Difícil até de explicar". Depois desta iniciativa, surdos que frequentavam a igreja e a REN, começaram a ter contato com outros surdos, dentre eles uma surda que veio do estado do Paraná e que era fluente em Libras e ajudou nessa disseminação. Essa interação do aprendizado de surdos e ouvintes, marcou a vida de muitos. Segundo IN1:

"Foi fantástico, aprendemos muito, uma bagagem muito importante (..), nessa época fizemos duas oficinas para capacitação na área de interpretação com o intérprete Marco Antonio Arriens ${ }^{5}$, participamos de um congresso internacional de surdos em Curitiba, no ano de 2005, fomos em um grupo de

\footnotetext{
5 “O pastor Marco Arriens é o grande formador técnico dos intérpretes no país, tendo atuado praticamente em todos os estados da nação, bem como em outros países. É o exemplo mais bem acabado do amalgama discursivo batista que sintetiza as produções científicas dessa nova surdez, teorias do teatro e a lógica da missão transcultural." (SILVA, 2013, p. 14).
} 


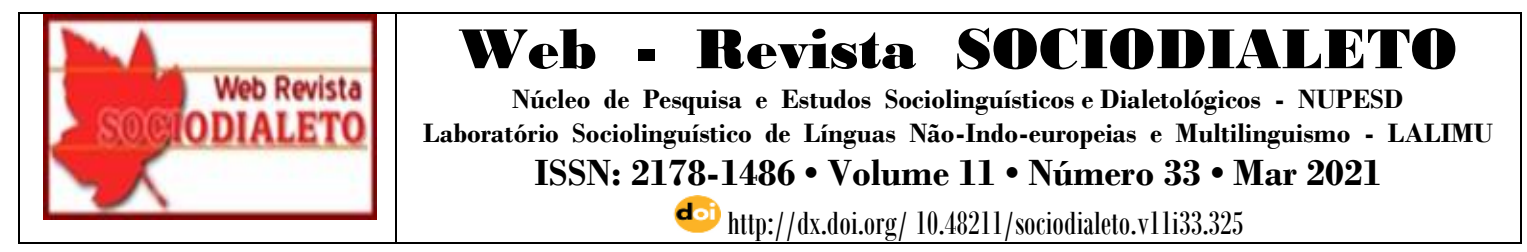

12 pessoas sendo 8 deles surdos, e todos esses momentos foram de grande aprendizagem da língua, da cultura surda, de ver, e de mostrar aos surdos daqui, os surdos como pessoas importantes na sociedade."

O trabalho dos envolvidos para a criação do Ministério com Surdos era totalmente voluntário e social e, não havia material de Libras para os estudos, como nos fala E1:

“Acredito que o nosso trabalho foi de 'formiguinha', mas a partir daí surgiram muitos outros, pois, essa foi a primeira vez que a comunidade surda da cidade teve um olhar diferenciado, ou seja, de ser importante e ter um segmento da sociedade, no caso, a igreja evangélica se importando e atendendo eles para o ensino de Libras, fomos a primeira igreja a se importar com eles, nem material tínhamos, aos poucos fomos adquirindo. Alguns conseguimos com uma outra igreja que possuía alguns materiais entre eles o alfabeto, hoje essa área é riquíssima em material, possuindo material evangélico até para crianças com músicas infantis sinalizadas, ou seja, cresceu muito, o que é diferente de quando começamos que tínhamos pouquíssimos materiais".

Essa fala demonstra as dificuldades e a força de vontade deste grupo para que o trabalho fosse desenvolvido com empenho. In1 nos relata que: "Em 2004 compramos VHS da Igreja Batista da Lagoinha com ensino de muitos sinais”. Esses materiais nas igrejas já estavam sendo produzidos. Segundo SILVA (2012, p. 102) confirma que:

No Brasil entre todas as denominações de matriz protestante, certamente as congregações batistas vinculadas à Convenção Batista Brasileira destacam-se nessa questão. Geralmente a prática de evangelização de surdos enquanto grupo étnico-linguístico, confirmada pela atuação de missionário, também intérprete, tem como ponto de partida agentes e congregações batistas, constituindo um movimento que tem se espraiado em uma rede que alcança inclusive a Igreja Católica. Cursos de formação de intérpretes ministrados por batistas, assim como dicionários e vídeos religiosos batistas com essa performance, explicam a sua posição de agência disseminadora. (SILVA, 2012, p. 102).

A aquisição de materiais possibilitou maior interação com o conhecimento da língua por ser mais visual e dinâmico. 


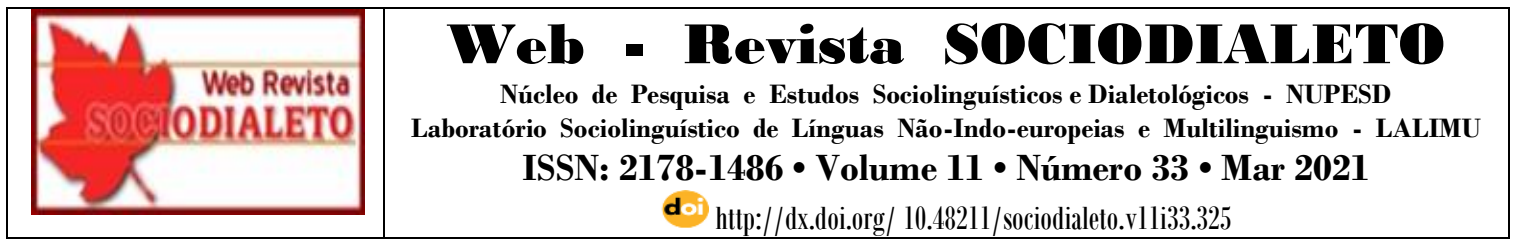

O fato histórico nos alia a vários personagens nas instituições e nos permite visualizar o início do aprendizado da língua de sinais, como nos disse um surdo : "aprendi os primeiros sinais na escola JK com a professora Telma de matemática mas poucos sinais. Ela me convidou para ir à II Igreja Batista para ter contatos com outros surdos. Fui à igreja e encontrei outros 15 surdos". O trabalho com surdo nas escolas era raro, nessa escola havia essa professora com um conhecimento inicial de Libras, mas sendo fruto do curso de Libras dessa igreja. Com a interação dos surdos que lá frequentavam, a partir do convite que a professora fez, foi que esse surdo pode ter contato com outros surdos. Em outra parte da entrevista, ele nos diz que:

"Lá6 havia intérprete. Neste momento comecei a ter contato com os surdo, mas o aprendizado e o estudo da língua não surgiram só ali, íamos aos sábados na casa de uma surda que conheci lá na igreja, comecei a ter contato com os outros surdos algumas vezes na semana. No projeto da REN estivemos juntos com esse grupo, bem como na igreja, passeios, cinema, sorveteria."

A partir desse grupo que estavam reunidos na igreja e na REN, a surda citada que tinha vindo do Paraná que era fluente em Libras, foi fundamental neste processo de aprendizagem e disseminação da língua de sinais aos surdos de Ji-Paraná. O papel de um surdo ensinando aos demais surdos, surte um efeito de identificação, em conformidade com a fala da In1: "Nossos surdos começaram a viajar para outros Estados e cidades. A interação com outros surdos fez com que o avanço da língua fosse muito rápido." Segundo Rangel e Stumpf (2010):

Quando professor e aluno falam a mesma língua, no caso, a língua de sinais, a comunicação deixa de ser um problema. Quando ambos são surdos, os interesses e a visão de mundo passam a ser os mesmos. A fluidez da comunicação possibilita as mais variadas trocas. (RANGEL; STUMPF, 2010, p. 87).

Ainda corroborando com Rangel e Stumpf, Eler (2018) diz:

A referência do professor surdo é muito importante para a constituição da identidade surda, o papel do professor surdo na educação desses sujeitos vai muito além do habitual em outras culturas. São nesses momentos com seus pares linguísticos que o surdo se vê igual ao outro

6 Referindo ao local onde encontrou com os surdos, a igreja. 


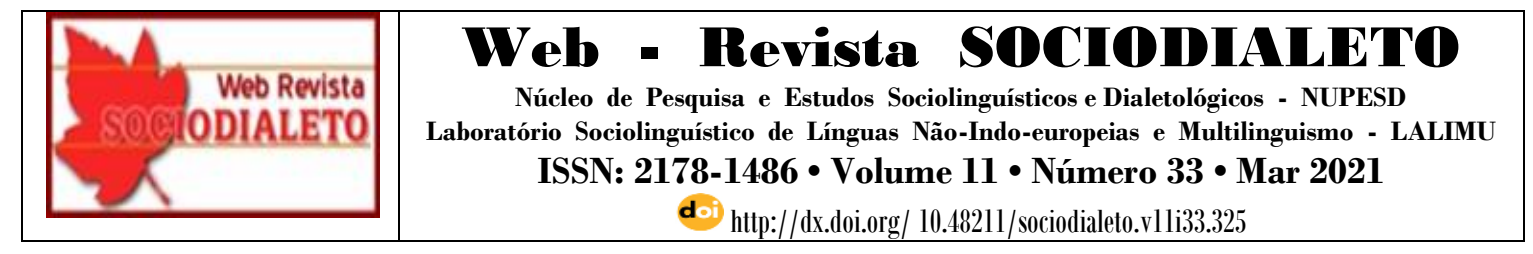

com representação de ser surdo e que não há nenhuma anormalidade nisso. (ELER, 2018, p. 80).

Com esse aprendizado e interação, os surdos se viram em outra posição como nos relata E2 ao dizer que os surdos saíram da posição de vender panfletos e começaram a se ver como pessoa capaz de trabalhar e viver em sociedade, de conquistar sua autonomia.

Em 2004, a REN organizou duas salas de recurso sendo uma no primeiro e outra no segundo distrito da cidade, em 2005 foi organizada outra sala de recurso no CEEJA (Centro de Estadual de Educação de Jovens e Adultos) para atender os alunos surdos jovens e adultos e foi organizado um projeto de atendimento de ensino modular que é umas das modalidades de educação do EJA para atender os surdos com professores bilíngues. Assim a Ren promoveu o primeiro curso de Libras, com dois surdos instrutores que haviam participado de uma capacitação de instrutores surdos pelo MEC, em Porto Velho.

Em 2004, foi criado a primeira Sala de Recursos pela secretaria Municipal de Ji-Paraná ou Atendimento Educacional Especializado - A.E.E. e a E3, conta que: “ $A$ gente estudava em 2004 através de um CD do INES (dicionário de Libras), fazíamos encontros semanais". A sala de recurso que era na Creche Maria Antônia mudou-se para a escola Jandinei Cella e era feito o atendimento com o ensino básico da língua de sinais no qual a professora nos relata acima o seu início de aprendizado foi por meio de CD. Segundo Santos (2014):

Em maio de 2004, começa o AEE para os alunos com deficiência, nesta mesma época três alunos surdos foram atendidos pela professora de Sala de Recursos. O aprendizado da Língua de Sinais foi estabelecido como meta profissional, com a intenção de melhorar a comunicação com os três surdos que eram atendidos. (SANTOS, 2014, p. 81).

No ano de 2005. Secretaria Municipal de Educação - SEMED promoveu outro curso de Libras com esses instrutores para professores e familiares de surdos. Em 2009, a E2 procurou o secretário da Secretaria da Administração - SEMAD e falou da importância do atendimento aos alunos surdos por um instrutor surdo e o município contratou o primeiro instrutor surdo, que passou a ensinar a Libras para as crianças 
surdas. Somente em 2011, a Gerente de Educação Especial, junto a uma vereadora por meio do Projeto de Lei no 2144 de 29/04/2011, foi criado a Gerência de Ensino de Surdos e a Coordenação de Ensino da Libras.

Em 2013, iniciou o Ensino Médio Bilíngue no CEEJA com professores ouvintes bilígues e um professor surdo, os conteúdos eram adaptados com materias que atendiam a pedagogia visual para o aprendizado dos alunos surdos atendendo ao currículo, e com assuntos atuais elencando exemplos da vivência do surdo, na área de exatas e a disciplina de biologia eram professores que tinham orientação dos professores bilíngue com intérpretes em sala de aula. Esse ensino resultou na conclusão de 14 surdos no ensino médio. Em 2014 houve o primeiro concurso público para professor de Libras na Universidade Federal de Rondônia, assim entrava os primeiros profissionais no ensino superior para a formação em Libras nos cursos de licenciatura. Neste mesmo ano teve a primeira Audiência Pública sobre Políticas Públicas para a Pessoa Surda em Ji-Paraná - participaram da audiência os envolvidos da pesquisa, In2, E2, profissionais da Universidade Federal de Rondônia, campus de Ji-Paraná e vários surdos. Em 2016 foi criado a Associação de Surdo e Familiares de Ji-Paraná, onde vários surdos se fizeram presentes e já se comunicando por intermédio da Libras. Em em 2017 foi implantado o projeto piloto da Sala Bilíngue na Escola de Ensino Fundamental Ruth Rocha, composto pela quantidade em média de 07 a 08 surdos de 04 a 13 anos. No curso de Pedagogia da Unir de Ji-Paraná, atualmente temos 05 surdos estudando com intérpretes e acompanhamento desses acadêmicos em projetos e assim serão os primeiros professores surdos a se formarem para atuar na educação de surdos do município.

As conquistas são orgulho destes militantes em prol da disseminação da Libras em busca de dias melhores em suas vidas, no qual todos possam no futuro ter direitos igualitário de surdos e ouvintes em sociedade bem como seu direito linguístico sendo respeitado.

\section{CONSIDERAÇÕES FINAIS}




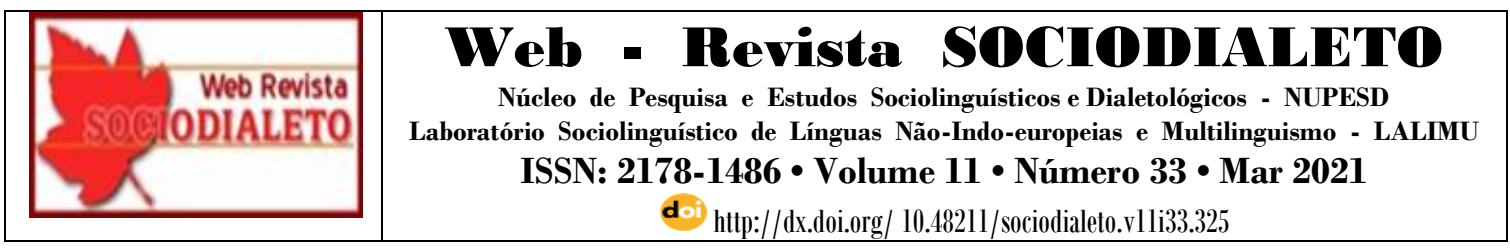

A O percurso do ensino da Libras ao longo dos séculos não foi uma realização fácil. Houve vários altos e baixos, entre eles os Congressos de Milão (1880) onde a Libras foi proibida. Mas mesmo com lutas os surdos e envolvidos pela causa não ficaram de cabeça baixa e lutaram pelo direito de usar os sinais.

No Brasil o contexto não foi diferente do restante do mundo, as conquistas desde o século XVIII foram marcadas com sacrifício e lutas, a criação do INES foi um marco difusor no desenvolvimento da LIBRAS. Esse grande acontecimento só foi possível graças as leis que vem avançando, mesmo que lentamente, no nosso país.

No município de Ji-Paraná as conquistas também são substanciais, a comunidade surda começou a ter voz ativa na comunidade graças ao apoio da Secretarias da Educação do Estado e Município e, da sociedade religiosa (Igreja Batista). Nos quais, tiveram profissionais, surdos, familiares e voluntários na elaboração e execução do ensino e aprendizado da Libras, visando a autonomia dos surdos por meio da aquisição da sua língua natural, no qual todos, puderam contribuir para o avanço e a disseminação da Libras e as conquistas atuais dos surdos no meio social.

\section{REFERÊNCIAS}

BRASIL. Decreto n⿳ 5.626, de 22 de dezembro de 2005. Diário oficial [da] República Federativa do Brasil, Poder Executivo, Brasília, DF, 23 dez. 2005. Disponível em: http://www.planalto.gov.br/ccivil_03/_Ato2004-2006/2005/Decreto/D5626.htm Acesso em: 25 out. 2018.

BRASIL. Decreto $\mathbf{n}^{\mathbf{0}}$ 42.728, de 3 de dezembro de 1957. Câmara dos Deputados. Disponível em: http://www2.camara.leg.br/legin/fed/decret/1950-1959/decreto-42728-3dezembro-1957- 381323-publicacaooriginal-1-pe.html Acesso em: 02 out. 2018.

BRASIL. Lei no 10.436, de 24 de abril de 2002. Diário oficial [da] República Federativa do Brasil, Poder Executivo, Brasília, DF, 25abr. 2002. Disponível em: Acesso em: 29 set. 2019.

BRASIL. Lei de Diretrizes e Bases. 9492 de 20 de dezembro de 1996. Disponível em: http://www.planalto.gov.br/ccivil_03/LEIS/L9394.htm Acesso em: 29 out. 2019.

ELER, R. R. de S. Língua de sinais Paiter Suruí: sinais do ambiente escolar. $1^{\mathrm{a}}$ ed. JiParaná-RO: Clube dos Autores, ISBN 978.65.00.01316-0, 2020. 


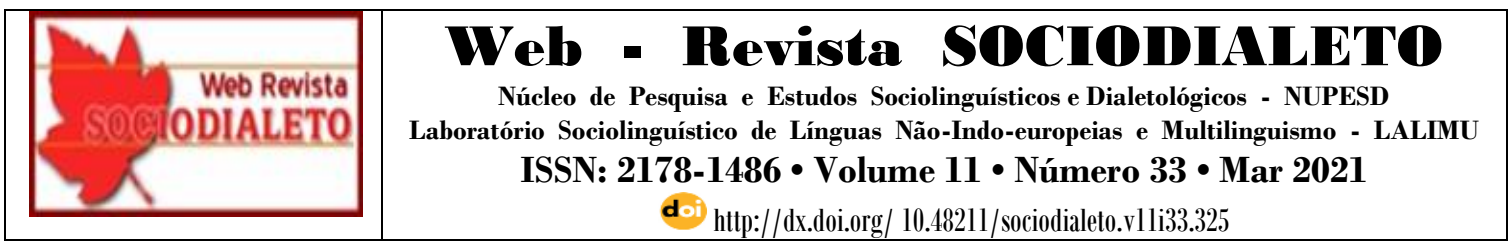

ELER, R. R, de S. Representação social surda e ouvinte: um olhar surdo sobre os ouvintes, reflexões necessárias. Revista Igarapé, v. 11, n. 2, 2018, p. 73-84.

FARIAS, S. P. de. Ao pé da letra não! Mitos que permeiam o ensino da leitura para os surdos. In: Quadros (org.). Estudos Surdos I - Petrópolis - RJ: Arara Azul, 2006, p. 252283.

RANGEL, G. M. M.; STUMPF, M. R. A pedagogia da diferença para o surdo. In: Lodi; Harrison; Campos (orgs.). Leitura e escrita no contexto da diversidade. Porto Alegre: Mediação, $3^{\text {a }}$ ed. 2010, p. 85-96.

REILY, L. Escola Inclusiva: Linguagem e mediação. São Paulo: Papirus, 2004.

ROSA, A da S. Entre a visibilidade da tradução da língua de sinais e a invisibilidade da tarefa do intérprete. Campinas, 2005. Dissertação (Mestrado em Educação) Universidade Estadual de Campinas.

SANTOS, J. P. da C. Os desafios da formação docente na aprendizagem dos alunos com surdez da rede municipal de Ji-Paraná-RO. Porto Velho, 2014. Dissertação (Mestrado em Educação) - Universidade Federal de Rondônia.

SILVA, C. A. de A. CULTURA SURDA: Agentes religiosos e a construção de uma identidade. São Paulo: Terceiro nome, 2012.

SILVA, C. A. de A. O papel de agentes religiosos na surdez: considerações sobre a constituição da cultura surda. Revista Espaço. ISSN 0103-7668. N. 39 Jan-Jun de 2013. p. 05-16. Rio de Janeiro: INES.

STROBEL, K. Apostila História da Educação de Surdos. Acesso em 20 de junho de 2020, disponível em: http://www.libras.ufsc.br/colecaoLetrasLibras/eixoFormacaoEspecifica/historiaDaEduc acaoDeSurdos/assets/258/TextoBase_HistoriaEducacaoSurdos.pdf

Recebido em: 04/09/2020 | Aprovado em: 01/11/2020. 